\title{
Who will increase their physical activity? Predictors of change in objectively measured physical activity over 12 months in the ProActive cohort
}

\author{
Rebecca K Simmons ${ }^{1}$, Esther MF van Sluijs1', Wendy Hardeman², Stephen Sutton², Simon J Griffin*1 and the ProActive
} project team

\begin{abstract}
Background: The aim was to identify predictors of change in objectively measured physical activity over 12 months in the ProActive cohort to improve understanding of factors influencing change in physical activity.

Methods: ProActive is a physical activity promotion trial that took place in Eastern England (1999-2004). 365 offspring of people with type 2 diabetes underwent measurement of physical activity energy expenditure (PAEE) using heart rate monitoring, fitness, and anthropometric and biochemical status at baseline and 1 year $(n=321)$. Linear regression was used to quantify the associations between baseline demographic, clinical, psychosocial and behavioural variables and change in PAEE over 12 months. This study is registered as ISRCTN61323766.

Results: ProActive participants significantly increased their PAEE by $0.6 \mathrm{kj} / \mathrm{min}$ (SD 4.2, $\mathrm{p}=0.006$ ) over one year, the equivalent of around 20 minutes brisk walking/day. Male sex and higher fitness at baseline predicted increase in PAEE. No significant associations were found for any other variables. Very few baseline demographic, clinical, psychosocial and behavioural predictors were associated with change in objectively measured physical activity.

Conclusions: Traditional baseline determinants of self-reported physical activity targeted by behavioural interventions may be relatively weak predictors of change in objectively measured physical activity. Further research is needed to improve our understanding of factors influencing change in physical activity to inform the development and targeting of interventions.
\end{abstract}

\section{Background}

Physical activity levels have been shown to predict risk of type 2 diabetes [1], cardiovascular disease [2], osteoporosis [3], some forms of cancers [4] and depression [5]. Encouraging people to increase their activity levels is therefore high on the public health agenda of most developed nations. Physical activity promotion interventions typically target individuals on the basis of risk according to one or more factors, including age, sex, current physical activity status, family history of disease, smoking, overweight or socio-economic status [6-12]. Results from trials suggest that these interventions work for some individuals but not for others. It is often those at highest risk who show the least change e.g. sedentary or disadvan-

* Correspondence: simon.griffin@mrc-epid.cam.ac.uk

${ }^{1}$ MRC Epidemiology Unit, Institute of Metabolic Science, Box 285, Addenbrooke's Hospital, Hills Road, Cambridge, CB2 0QQ, UK Full list of author information is available at the end of the article taged individuals, smokers, and the elderly $[7,8,13,14]$. If it were possible to identify those who are most likely to respond positively to particular health promotion programmes, health resources could be allocated to appropriate sub-groups, who are either more or less likely to change. Selection of target groups and development of interventions could thus be enhanced by a better understanding of the predictors of change in physical activity among relevant populations.

Most studies exploring predictors of physical activity behaviour change measure current or future behaviour, and frequently focus on sporting activities [15]; the majority also rely on self-reported physical activity [14,1618]. Therefore, we aimed to investigate whether selected predictors were associated with change in objectively measured physical activity over 12 months in a health promotion trial cohort (ProActive) to inform subsequent 
intervention development and targeting. As physical activity behaviour is influenced by a variety of factors from multiple domains [19], we included a wide range of baseline predictors. We examined demographic variables, including age, sex, and socio-economic status, that have already been shown to be predictive of physical activity, or change in physical activity [20]. As the behavioural determinants targeted in the intervention were informed by the Theory of Planned Behaviour based on meta-analytic evidence for their ability to predict behaviour $[15,21$ 24], we included variables which have been shown to be positive proximal predictors of physical activity (intention and perceived behavioural control), and included past activity behaviour, which has also been to shown to predict future behaviour [15]. Similarly, BMI was considered as a potential predictor as it has previously been linked to physical activity behaviour change $[16,17,25]$. We also looked at variables that have not previously been examined in order to generate new hypotheses regarding the prediction of change in physical activity. These included clinical variables, such as blood pressure and cholesterol, and psychosocial variables, such as selfreported anxiety and health status, which may not be causally related to change, but may form part of a pragmatic strategy to identify those who might benefit from changing their physical activity behaviour.

\section{Methods}

ProActive is a randomised trial of a theory- and evidencebased behavioural intervention to increase physical activity among individuals who are at increased risk of the consequences of a sedentary lifestyle due to their family history of type 2 diabetes [26]. Potential participants were identified via diabetes registers and medical records of family history in 20 general practices in East Anglia, England.

Participants were initially recruited through their parents who were identified on diabetes registers. 2,631 patients were approached and 2,025 (77\%) replied, yielding 1,238 potentially eligible offspring who were invited to take part in the study. In seven of the practices, 1,340 patients with a recorded family history of diabetes were written to, and 896 (67\%) responses were received, with 283 patients interested and eligible. Potential participants were asked to fill in a short screening activity questionnaire, describing occupational and leisure activity, based on published questionnaires $[27,28]$, to exclude very active individuals. Out of 1,123 individuals who completed the questionnaire ( $74 \%$ response rate), 323 refused to participate, 411 met the exclusion criteria and 24 took part in a pilot study. Therefore, 365 individuals aged 3050 years and reporting low levels of activity were randomly assigned to one of three interventions: (i) a theorybased leaflet with brief advice; (ii) the leaflet plus an intensive theory-based behaviour change programme delivered at participants' homes; or (iii) the leaflet plus the same intervention programme delivered by telephone. The programme was delivered by trained facilitators (for further details see [29]). It aimed to support increases in physical activity through a range of self-regulatory skills including goal setting, action planning, selfmonitoring, and relapse prevention. Information on a range of demographic, clinical, psychosocial and behavioural variables was collected from participants, as well as objective measurement of physical activity (using heart rate monitoring) at baseline and one year follow-up. Main trial results indicated that the intensive theory-based behavioural intervention was no more effective than the theory-based brief advice leaflet alone in increasing objectively measured physical activity levels at one year [30]. However, all participants increased their physical activity, on average, by the equivalent of 20 minutes brisk walking a day. In order to examine the predictors of increased physical activity, we pooled the trial arms to conduct a cohort analysis. Ethical approval was obtained from the Eastern England MREC (02/5/53) and relevant Primary Care Trusts; all participants gave written informed consent. Full details of the study have been reported elsewhere [26].

\section{Measurement of physical activity energy expenditure}

Participants wore heart rate (HR) monitors (Polar Electro Ltd, Kemple, Finland) continuously during the waking hours over 4 days following their visit to the study centre. Resting energy expenditure (REE) was calculated by the Weir formula [31] using $\mathrm{VO}_{2}$ and $\mathrm{VCO}_{2}$ measurements obtained in the fasting state, after approximately $10 \mathrm{~min}$ utes of supine rest using the same indirect calorimetry system as previously described [26]. Physical activity energy expenditure (PAEE) was measured using the flex HR method, which has been described in detail elsewhere $[32,33]$. Below the flex HR point, energy expenditure (EE) was assumed to be equivalent to REE. EE above the flex point was predicted from the individual HR-EE regression line. PAEE was calculated by subtracting REE from the estimated average daily energy expenditure, and thereafter averaged over the 4-day period.

\section{Clinical predictors}

Participants attended the study centre after an overnight fast and a sample of venous blood was taken. Total cholesterol was measured using standard enzymatic methods, as previously described [26]. Glycosylated haemoglobin $\left(\mathrm{HbA}_{1 \mathrm{c}}\right)$ was measured on fresh EDTA blood samples using high-performance liquid chromatography. Weight was measured on standard calibrated scales and height was measured using a rigid stadiometer. BMI was calculated as weight $(\mathrm{kg})$ divided by height 
squared $\left(\mathrm{m}^{2}\right)$. Systolic and diastolic blood pressure were measured in a seated position using an automated Accutorr sphygmomanometer (Accutorr, Cambridge, UK) three times at one-minute intervals; the mean of these measurements was used in the analysis [26]. Aerobic fitness $\left(\mathrm{VO}_{2 \max }\right)$ was predicted as oxygen uptake at estimated maximal HR (220 minus age) by extrapolation of the regression line established during the individual calibration for the relationship between oxygen consumption and HR during a submaximal graded treadmill exercise test.

\section{Psychosocial predictors}

Self-report measures of well-being and quality of life were collected, including the SF-36 health survey [34], the short form of Spielberger's State Anxiety Inventory (STAI) [35] and a measure of current health status (EuroQol). In brief, the SF-36 is a health survey of 36 items which can be used to generate psychometrically-based physical and mental health summary measures. The STAI consists of six, 4-point Likert scales, and has been shown to correlate well $(r>0.9)$ with the results of the longer questionnaire from which it was derived [35], which is in turn associated with indicators of anxiety [36]. The STAI used in this study measures state (current state of anxiety or mood) rather than trait (recurring or individual characteristics of anxiety or mood) anxiety [35]. The EuroQol is a health "thermometer" which asks responders to mark on a scale of 0 to 100 their current health status, from "Worst imaginable health state (0)" to "Best imaginable health state (100)". We also collected data on cognitive predictors of physical activity, based on the Theory of Planned Behaviour, that were hypothesized to be directly associated with behaviour change [29]. Items were developed according to Theory of Planned Behaviour guidelines [37] and measured on a Likert-type scale ranging from 1 (strongly disagree) to 5 (strongly agree) [38], and averaged to calculate overall scores. The questionnaire included two items to assess perceived behavioural control ('it would be difficult for me to be more physically active in the next 12 months even if I wanted to' (score reversed), 'I am confident that I could be more physically active in the next 12 months, if I wanted to') and intention ('I intend to be more physically active in the next 12 months', 'it is likely that I will be more physically active in the next 12 months'). Cronbach's alpha for internal consistency was 0.54 for perceived behavioural control, and 0.77 for behavioural intention at baseline.

\section{Behavioural predictors}

Past activity behaviour was measured using the EPICNorfolk physical activity questionnaire (EPAQ-2), which has previously been validated using objective heart rate monitoring [39]. Participants answered questions about smoking status and weekly alcohol consumption in a general health questionnaire.

\section{Statistical analyses}

Descriptive summary statistics were calculated separately for men and women using means and SDs at baseline and follow-up. T-tests were used to examine whether there were any differences in baseline characteristics between those with and without follow-up data. We used linear regression to model baseline demographic, clinical, behavioural and psychosocial variables separately against PAEE at follow-up. These models were adjusted for baseline PAEE to describe change in this variable over time. We also ran a multivariable regression model to examine PAEE change, mutually adjusting for all significant predictor variables $(\mathrm{p}<0.05)$, to establish which variables were independently associated with the outcome. The residuals of all linear regression models were checked to ensure they were normally distributed. Models were also run separately by trial arm and by sex. As results were similar in the three trial arms and by sex (data not shown), the data were pooled and results from linear regression models conducted in the whole cohort are presented. Type I error was set at 0.05 for all tests. All data were analyzed in continuous form using Stata Version 10.0. (STATA Corp., College Station, Texas, USA).

\section{Results}

Complete data on PAEE, aerobic fitness, anthropometry and biochemical measures were available in 365 participants at baseline and 321 participants at 12 months. Participants with missing data at follow-up were similar to those with complete data on age, sex, and social class, as well as baseline BMI, PAEE and fitness (all p-values > 0.05 , data not shown).

Table 1 shows characteristics of participants at baseline and follow-up stratified by sex $(\mathrm{n}=321)$. Men had significantly higher blood pressure and $\mathrm{HbA}_{1 \mathrm{c}}$ levels than women at baseline, and reported higher levels of alcohol consumption. Statistically significant differences were also observed for PAEE and $\mathrm{VO}_{2 \max }$, with men having higher levels of PAEE and fitness than women at baseline.

For men, the only clinical variables that changed significantly over time were systolic and diastolic blood pressure, which reduced, and $\mathrm{HbA}_{1 \mathrm{c}}$, where a small increase was observed. Perceived behavioural control showed a small decrease, while significant improvements were seen for self-reported health status, anxiety, physical functioning and mental health. Men increased their physical activity (PAEE) from 8.2 to $9.1 \mathrm{kj} / \mathrm{min}$ over the year, but this change was not statistically significant. For women, small but significant increases were seen for BMI and $\mathrm{HbA}_{1 \mathrm{c}}$, with significant decreases in systolic and diastolic blood pressure over the same period. Women reported a 
Table 1: Characteristics of ProActive participants with complete baseline and follow-up data, stratified by sex, $n=321$

\begin{tabular}{|c|c|c|c|c|}
\hline & \multicolumn{2}{|c|}{$\begin{array}{c}\text { Men } \\
(\mathrm{N}=129)\end{array}$} & \multicolumn{2}{|c|}{$\begin{array}{l}\text { Women } \\
(N=192)\end{array}$} \\
\hline & Baseline & Follow-up & Baseline & Follow-up \\
\hline Age (years) & $40.2(5.8)$ & - & $40.8(6.1)$ & - \\
\hline $\begin{array}{l}\text { Social class (based on the Index } \\
\text { of Multiple }\end{array}$ & $4.2(0.9)$ & - & $4.2(0.9)$ & - \\
\hline \multicolumn{5}{|l|}{$\begin{array}{l}\text { Deprivation score } 1-5 ; 5 \\
\text { representing highest social } \\
\text { class) }\end{array}$} \\
\hline BMI $\left(\mathrm{kg} / \mathrm{m}^{2}\right)$ & $28.2(4.3)$ & $28.3(4.3)$ & $27.6(5.2)$ & $27.8(5.4)^{a}$ \\
\hline Systolic blood pressure (mmHg) & $127.1(11.3)$ & $124.5(11.3)^{\mathrm{a}}$ & $120.6(13.8)^{b}$ & $116.8(13.4)^{c}$ \\
\hline $\begin{array}{l}\text { Diastolic blood pressure } \\
(\mathrm{mmHg})\end{array}$ & $81.4(8.8)$ & $79.6(9.7)^{a}$ & $76.2(9.3)^{b}$ & $73.9(9.9)^{c}$ \\
\hline $\mathrm{HbA}_{1 \mathrm{c}}(\%)$ & $5.3(0.5)$ & $5.5(0.7)^{c}$ & $5.2(0.5)^{b}$ & $5.3(0.4)^{c}$ \\
\hline Total cholesterol (mmol/l) & $5.3(1.0)$ & $5.3(1.0)$ & $5.1(0.9)$ & $5.2(1.0)$ \\
\hline $\begin{array}{l}\text { Perceived behavioural control } \\
\text { (scale } 1-5 ; 5 \text { representing } \\
\text { highest perceived control) }\end{array}$ & $3.8(0.6)$ & $3.6(0.7)^{\mathrm{a}}$ & $3.9(0.6)$ & $3.6(0.7)^{c}$ \\
\hline $\begin{array}{l}\text { Intention (scale } 1-5 ; 5 \\
\text { representing highest level of } \\
\text { intention) }\end{array}$ & $3.7(0.6)$ & $3.7(0.7)$ & $3.7(0.6)$ & $3.6(0.7)^{\mathrm{a}}$ \\
\hline $\begin{array}{l}\text { Current health status (scale } 0- \\
100, \text { where } 0=\text { worst imaginable } \\
\text { health to } 100=\text { best imaginable } \\
\text { health state) }\end{array}$ & $77.8(14.7)$ & $80.8(13.6)^{a}$ & $79.0(15.7)$ & $81.7(12.7)^{\mathrm{a}}$ \\
\hline $\begin{array}{l}\text { Spielberger state anxiety score } \\
\text { (scale } 20-80, \text { where } 80 \\
\text { represents the highest possible } \\
\text { score) }\end{array}$ & $36.4(11.6)$ & $33.8(10.7)^{a}$ & $38.6(12.6)$ & $37.4(12.0)$ \\
\hline $\begin{array}{l}\text { SF-36 physical functioning score } \\
\text { (scale } 0-100 \text {, with } 100 \text { indicating } \\
\text { highest level of self-reported } \\
\text { physical health) }\end{array}$ & $90.9(16.5)$ & $95.5(7.9) \mathrm{c}$ & $90.2(14.2)$ & $93.0(12.4)^{\mathrm{a}}$ \\
\hline $\begin{array}{l}\text { SF- } 36 \text { mental health score (scale } \\
0-100 \text {, with } 100 \text { indicating } \\
\text { highest level of self-reported } \\
\text { mental health) }\end{array}$ & $76.6(15.0)$ & $79.2(15.0)^{a}$ & $74.0(14.9)$ & $75.4(16.7)$ \\
\hline $\begin{array}{l}\text { Self-reported alcohol (total } \\
\text { units/wk) }\end{array}$ & $10.6(10.6)$ & N/A & $4.6(5.7)^{b}$ & N/A \\
\hline $\begin{array}{l}\text { Self-reported smoking status, n } \\
\text { (\%) current smoker }\end{array}$ & $27(20.9)$ & $25(19.4)$ & $29(15.1)$ & $26(13.5)$ \\
\hline PAEE (kj/min) & $8.2(5.0)$ & $9.1(5.4)$ & $4.6(3.5)^{b}$ & $5.1(3.2)^{a}$ \\
\hline $\mathrm{VO}_{2 \max }(\mathrm{I} / \mathrm{min})$ & $4.0(0.9)$ & $4.0(0.9)$ & $2.7(0.6)^{b}$ & $2.8(0.6)$ \\
\hline
\end{tabular}

Data are means (SD), except where stated otherwise. Means were compared using paired t-tests for baseline vs follow-up, and t-tests for men vs women at baseline. Proportions were compared using McNemar's test for baseline vs follow-up and a chi-squared test for men vs women at baseline. $\mathrm{N} / \mathrm{A}=$ not available; ${ }^{\mathrm{a}} \mathrm{p}<0.05$ for baseline vs follow-up (separately in men and women); ${ }^{\mathrm{b}} p<0.001$ for women vs. men at baseline; ${ }^{\mathrm{c}} \mathrm{p}<$ 0.001 for baseline vs follow-up (separately in men and women) 
small decrease in perceived behavioural control and intention, but a significant increase in health status and physical functioning. Increases in physical activity and fitness were observed, with the change in PAEE reaching statistical significance. Overall, the whole ProActive cohort $(\mathrm{n}=321)$ significantly increased their PAEE by 0.6 $\mathrm{kj} / \mathrm{min}(\mathrm{SD} 4.2$, t-statistic $=2.8, \mathrm{p}=0.006)$ over one year.

Table 2 shows the associations between demographic, clinical, psychosocial and behavioural variables at baseline and change in PAEE $(\mathrm{kj} / \mathrm{min})$ over one year. Male sex was associated with a significant increase in PAEE over one year, while age and social class did not demonstrate any association. Individuals with a higher level of fitness at baseline were more likely to increase their PAEE over one year. No significant associations were seen for any of the remaining clinical or psychosocial variables and PAEE. Weekly alcohol intake and baseline PAEE were positively associated with PAEE at follow-up. Each model explained 32 to $37 \%$ of the variance in one year PAEE change. However, baseline PAEE accounted for most of the variance in each model, with predictor variables typically adding less than $1 \%$ to the explained variance.

After adjusting for all significant predictor variables in a multivariable regression model (baseline PAEE, sex, fitness, and self-reported alcohol consumption), baseline PAEE ( $\beta 0.454 ; 95 \%$ CI 0.349 to 0.560$)$, sex ( $\beta 1.319 ; 95 \% \mathrm{CI}$ 0.189 to 2.449$)$ and fitness ( $\beta 0.668$; 95\%CI 0.064 to 1.273 ) remained as independent predictors of change in PAEE in this model. The variance explained by this model was $39 \%$.

\section{Discussion}

This study aimed to identify demographic, clinical, psychosocial and behavioural predictors of change in objectively measured physical activity over a one year period. Our findings suggest that very few of the variables measured at baseline in the ProActive trial cohort predicted change in PAEE over one year. Male sex and higher fitness levels were independently associated with significant increases in PAEE. Weekly alcohol intake was a significant predictor of change in PAEE but this association became non-significant when sex and fitness were included in the model. No significant associations with change were seen for any other variables. The finding that men were more likely than women to increase their physical activity over one year has been shown in some interventions [40] but not in others [12,41]. To the best of our knowledge, the result that individuals with higher fitness at baseline were more likely to increase their objectively measured physical activity is a novel finding.

\section{Comparison with other literature}

In general, our results do not support the limited literature showing associations between certain socio-demo- graphic, psychosocial and behavioural variables, and change in physical activity behaviour $[14,42]$. Younger age is usually associated with increased physical activity, both cross-sectionally and over time [20]. We did not show a significant relationship with age, though the range was quite restricted (30-50 years). Furthermore, most previous results come from observational studies rather than intervention studies, such as the ProActive trial, in which all participants were encouraged to increase their activity levels. Prospective studies that have examined the relationship between baseline predictors and level of physical activity at follow-up have demonstrated associations with self-efficacy [14,41,43-45]; perceived behavioural control [46]; past behaviour [43]; perceived benefits or views of exercise $[45,47]$; and the participant's belief that physical activity was important for their health [13]. However, the questions derived from the Theory of Planned Behaviour to characterize perceived behavioural control and intention about becoming more physically active over the next year did not predict change in physical activity in this cohort. These findings suggest that such measures may not be useful in identifying subgroups of participants who are more or less likely to make long-term changes in their activity levels. The positive association between fitness and change in PAEE is a novel finding. As fitness is partially genetically determined [48], for two people starting at the same physical activity level but with different fitness levels, it may be easier for the individual with a higher fitness level to increase their physical activity.

One of the challenges in comparing our results to those found in other studies is the difference in methods used to measure physical activity. Previous studies usually measured current or future self-reported behaviour, and frequently focused on sporting activities [15], while we examined change in everyday objective physical activity behaviour. When physical activity behaviour and physical activity determinants are both measured using the same method e.g. by self-report questionnaire, associations may be due, at least in part, to commonality in response patterns to these measures ("common method variance") [49]. Consequently, when physical activity is measured by a different method (e.g. heart rate monitoring), part of the correlation explained by common method variance disappears, producing lower, non-significant or non-existent associations. Indeed, studies using objectively measured behaviour are less likely to observe significant associations with predictors, such as those based on the theory of planned behaviour, than those using selfreported behaviour [22]. However, when we examined the relationship between the same predictors and change in self-reported physical activity, we found only a few significant associations (for male sex, and higher fitness and BMI at baseline), indicating that common method variance cannot fully explain the lack of association with 
Table 2: Associations between baseline demographic, clinical, psychosocial and behavioural variables with change in PAEE (kj/min) over one year in the ProActive trial cohort, $n=321$

\begin{tabular}{|c|c|c|}
\hline Baseline variable & $\begin{array}{l}\text { PAEE (kj/min) unstandardised b-coefficient } \\
(95 \% \mathrm{Cl}) \mathrm{a}\end{array}$ & P-value \\
\hline \multicolumn{3}{|l|}{ Demographic } \\
\hline Age (years) & $-0.043(-0.114$ to 0.028$)$ & 0.233 \\
\hline Sex $($ female $=0 ;$ male $=1)$ & 2.181 (1.286 to 3.075$)$ & $<0.001$ \\
\hline $\begin{array}{l}\text { Social class (based on the } \mathrm{IMD}^{\mathrm{b}} \text { score 1-5; } 5 \\
\text { representing highest social class) }\end{array}$ & $0.283(-0.204$ to 0.771$)$ & 0.254 \\
\hline \multicolumn{3}{|l|}{ Clinical } \\
\hline $\mathrm{BMI}\left(\mathrm{kg} / \mathrm{m}^{2}\right)$ & $0.019(-0.068$ to 0.105$)$ & 0.675 \\
\hline Systolic blood pressure $(\mathrm{mm} \mathrm{Hg})$ & $0.000(-0.032$ to 0.031$)$ & 0.983 \\
\hline Diastolic blood pressure (mm Hg) & $-0.016(-0.060$ to 0.029$)$ & 0.483 \\
\hline $\mathrm{HbA}_{1 \mathrm{c}}(\%)$ & $-0.146(-0.993$ to 0.702$)$ & 0.736 \\
\hline Total cholesterol (mmol/l) & $-0.204(-0.633$ to 0.225$)$ & 0.350 \\
\hline $\mathrm{VO}_{2 \max }(\mathrm{I} / \mathrm{min})$ & $1.138(0.644$ to 1.631$)$ & $<0.001$ \\
\hline \multicolumn{3}{|l|}{ Psychosocial } \\
\hline Perceived behavioural control ( 1 to 5$)^{c}$ & $-0.086(-0.795$ to 0.623$)$ & 0.812 \\
\hline Intention $(1 \text { to } 5)^{c}$ & $0.281(-0.390$ to 0.953$)$ & 0.410 \\
\hline $\begin{array}{l}\text { Current health status (scale } 0-100 \text {, where } 0 \\
=\text { worst imaginable health to } 100=\text { best } \\
\text { imaginable health state) }\end{array}$ & $-0.019(-0.047$ to 0.008$)$ & 0.171 \\
\hline Anxiety score (Spielberger) & $0.012(-0.023$ to 0.047$)$ & 0.494 \\
\hline SF-36 physical functioning score & $-0.018(-0.047$ to 0.010$)$ & 0.208 \\
\hline SF-36 mental health score & $-0.016(-0.043$ to 0.012$)$ & 0.275 \\
\hline \multicolumn{3}{|l|}{ Behavioural } \\
\hline $\operatorname{PAEE}(\mathrm{kj} / \mathrm{min})^{\mathrm{d}}$ & 0.599 (0.506 to 0.691$)$ & $<0.001$ \\
\hline $\begin{array}{l}\text { Self-reported physical activity index (met } \\
\text { hours/week) }\end{array}$ & $0.008(0.000$ to 0.016$)$ & 0.055 \\
\hline Self-reported alcohol (total units/wk) & 0.059 (0.009 to 0.109$)$ & 0.022 \\
\hline $\begin{array}{l}\text { Self-reported smoking status }(0=\text { never } / \\
\text { ex; } 1=\text { current })\end{array}$ & $1.064(-0.098$ to 2.225$)$ & 0.072 \\
\hline
\end{tabular}

${ }^{a}$ Adjusted for baseline PAEE; ${ }^{b}$ Index of multiple deprivation; ${ }^{c}$ Theory of Planned Behaviour; ${ }^{d}$ Unadjusted

objectively measured physical activity. A number of other reasons for the lack of association between baseline variables and physical activity change might also be considered.

Potential reasons for lack of associations

First, previous work has focused on selected populations with a short follow-up [15]. We examined a sample of middle-aged, slightly overweight individuals, identified through primary care registers via a first degree family history of diabetes. This group represents a sub-group of the population who would benefit from increased overall physical activity. The longer than usual follow-up period in the ProActive trial (one year) may account for some of the differences found between this and other studies. Sec- 
ond, although our sample size was larger than many other physical activity promotion trials, there may have been a lack of heterogeneity in the cohort. This would have reduced our power to detect any associations with physical activity. However, the large standard deviations and ranges for change in PAEE indicate that this is unlikely to be the case.

Third, we did not measure some of the variables that have been shown to be associated with physical activity behaviour, including environmental and social factors, and may therefore have focused on the weaker determinants of objectively measured physical activity behaviour. King et al, for example, found that neighborhood environment is a potential predictor of physical activity maintenance over two years, though a self-report measure of physical activity was used [14]. Wider collective determinants of physical activity may act independently or interact with psychosocial correlates to influence physical activity behaviour, though these relationships have not been clearly elucidated $[50,51]$. Furthermore, some of the associations may have been weaker in our study because of the low reliability of the measures, e.g. Cronbach's alpha was only 0.54 for perceived behavioural control.

Fourth, since all participants were at risk due to their family history of disease, we cannot examine whether this factor was an important predictor of change. Similarly, all participants were subject to trial recruitment procedures and objective physical activity measurement (albeit without feedback), and the effects of this may have diluted associations reported in other studies. However, individuals in observational studies have also been recruited and measured, and these processes have been linked to behaviour change [52]. Objective measurement of physical activity in the ProActive cohort may have increased the saliency of this behaviour and prompted self-monitoring, an effective behaviour change technique in its own right.

Fifth, the precision in the methods we used to assess PAEE may also have contributed to the lack of observed associations. PAEE from individually calibrated heart rate monitoring is an integrated measure of energy expenditure above rest calculated from free-living heart rate data. In sedentary populations, much of the daytime is spent in the region around the flex heart rate, which is used to discriminate between rest and physical activity. The association between heart rate and energy expenditure is less precise in this region, which may reduce the accuracy of predicted PAEE on an individual level [53]. Finally, we conducted multiple significance tests $(>20)$ between baseline predictors and change in PAEE which may have led to an increased risk of Type 1 errors. It is unclear whether the few significant observations represent real or chance associations. The exploratory and post-hoc nature of our analyses mean that results should be interpreted with caution.

However, the ProActive trial allowed objective measurement of physical activity over a period of 12 months in a well-defined and accessible group of individuals who were at increased risk of diabetes and who would benefit from increases in physical activity. There was a high follow-up rate (88\%). Objective measurement of physical activity reduces the error and bias commonly associated with self-report measures, and PAEE has been extensively validated in the laboratory and during free-living conditions $[53,54]$. Furthermore, we measured a wide range of potential predictors from a variety of domains, including clinical, behavioural, demographic and psychosocial variables.

\section{Future research implications}

Systematic application of methods aimed at increasing our understanding of how predictors from different domains influence physical activity change over time remains scarce [42]. Yet, the potential benefit of examining these variables for physical activity, diet and weight control is well recognized in the behavioural and social sciences literature [55]. Identifying predictors of change in physical activity, regardless of whether the predictors are causally related to change, could help the targeting of appropriate sub-groups for intervention and improve efficacy. We could target those who were likely to change with brief interventions, such as action planning or goal setting in combination with self-monitoring, or target those who were unlikely to change with more intensive interventions [56]. Results from this analysis suggest that trying to predict who will change their physical activity behaviour is not straightforward. Ideally we would target people on the basis of both their risk of future health problems and the likelihood that they would change in response to intervention, but further research is needed to improve our understanding of determinants of change in physical activity behaviour. In addition, the lack of associations between traditional determinants of selfreported physical activity and behaviour change in this cohort suggests these factors may not be the most appropriate to inform intervention development.

\section{Conclusions}

This study is one of largest to allow prospective examination of these variables with objective measurement of physical activity over one year. In contrast with previously described determinants of self-reported physical activity, very few baseline demographic, clinical, behavioural and psychosocial variables were associated with change in objectively measured physical activity over 12 months in the ProActive trial cohort. Our results suggest that predicting who will increase their physical activity is diffi- 
cult, and that effective interventions may therefore need to be informed by other categories of determinants not measured here. Further research is needed to improve prediction of change in physical activity, and inform the development and targeting of interventions. As many of our prediction models were hypothesis-generating, our results will need validating in other experimental studies.

\section{Abbreviations}

EE: Energy expenditure; $\mathbf{H b A}_{1 \mathbf{c}}$ : Glycosylated haemoglobin; HR: Heart rate; MREC: Multi-centre Research Ethics Committee; PAEE: Physical activity energy expenditure; REE: Resting energy expenditure; STAI: Spielberger's State Anxiety Inventory;

\section{Competing interests}

The authors declare that they have no competing interests.

\section{Authors' contributions}

SJG conceived of the study question. RKS completed the analysis and drafted the manuscript. SJG, WH and SS participated in the study design and coordination. All authors contributed to analysis and interpretation of data, and read and approved the final manuscript.

\section{Acknowledgements}

With thanks to the study participants and practice teams for their collaboration and work in helping with recruitment. Also thanks to Ulf Ekelund for physical activity measurement advice, to Tom Fanshawe for statistical help and to Ann Louise Kinmonth for her helpful comments. The ProActive research team, includes, besides the authors, Kate Williams, Julie Grant, A Toby Prevost, William Hollingworth, David Spiegelhalter (PI), Nicholas Wareham (PI) and Ann Louise Kinmonth (PI).

This work was supported by the Medical Research Council; National Health Service Research \& Development; the Royal College of General Practitioners Scientific Foundation, and Diabetes UK (ref no. RG35259).

\section{Author Details}

'MRC Epidemiology Unit, Institute of Metabolic Science, Box 285 Addenbrooke's Hospital, Hills Road, Cambridge, CB2 0QQ, UK and ' General Practice \& Primary Care Research Unit, Institute of Public Health, Forvie Site, Robinson Way, Cambridge, CB2 OSR, UK

Received: 26 August 2009 Accepted: 30 April 2010 Published: 30 April 2010

\section{References}

1. Laaksonen DE, Lindstrom J, Lakka TA, Eriksson JG, Niskanen L, Wikstrom K, Aunola S, Keinanen-Kiukaanniemi S, Laakso M, Valle TT, et al.: Physical activity in the prevention of type 2 diabetes: the Finnish diabetes prevention study. Diabetes 2005, 54(1):158-165.

2. Lakka TA, Venalainen JM, Rauramaa R, Salonen R, Tuomilehto J, Salonen JT: Relation of leisure-time physical activity and cardiorespiratory fitness to the risk of acute myocardial infarction. N Engl J Med 1994, 330(22):1549-1554.

3. Nelson ME, Fiatarone MA, Morganti CM, Trice I, Greenberg RA, Evans WJ: Effects of high-intensity strength training on multiple risk factors for osteoporotic fractures. A randomized controlled trial. Jama 1994, 272(24):1909-1914

4. Batty $D$, Thune I: Does physical activity prevent cancer? Evidence suggests protection against colon cancer and probably breast cancer. Bmj 2000, 321(7274):1424-1425.

5. Farmer ME, Locke BZ, Moscicki EK, Dannenberg AL, Larson DB, Radloff LS: Physical activity and depressive symptoms: the NHANES Epidemiologic Follow-up Study. Am J Epidemiol 1988, 128(6):1340-1351.

6. Harland J, White M, Drinkwater C, Chinn D, Farr L, Howel D: The Newcastle exercise project: a randomised controlled trial of methods to promote physical activity in primary care. Bmj 1999, 319(7213):828-832.

7. Taylor AH, Doust J, Webborn N: Randomised controlled trial to examine the effects of a GP exercise referral programme in Hailsham, East
Sussex, on modifiable coronary heart disease risk factors. J Epidemiol Community Health 1998, 52(9):595-601.

8. Hillsdon M, Thorogood M, White I, Foster C: Advising people to take more exercise is ineffective: a randomized controlled trial of physical activity promotion in primary care. Int J Epidemiol 2002, 31(4):808-815.

9. HDA: The effectiveness of public health interventions for increasing physical activity among adults:a review of reviews. NHS; 2004.

10. Kahn EB, Ramsey LT, Brownson RC, Heath GW, Howze EH, Powell KE, Stone EJ, Rajab MW, Corso P: The effectiveness of interventions to increase physical activity. A systematic review. Am J Prev Med 2002, 22(4 Suppl):73-107.

11. Halbert JA, Silagy CA, Finucane PM, Withers RT, Hamdorf PA: Physical activity and cardiovascular risk factors: effect of advice from an exercise specialist in Australian general practice. Med J Aust 2000 173(2):84-87.

12. Writing Group for the Activity Counseling Trial Research Group: Effects of physical activity counseling in primary care: the Activity Counseling Trial: a randomized controlled trial. Jama 2001, 286(6):677-687.

13. Burton LC, Shapiro S, German PS: Determinants of physical activity initiation and maintenance among community-dwelling older persons. Prev Med 1999, 29(5):422-430.

14. King AC, Marcus B, Ahn D, Dunn AL, Rejeski WJ, Sallis JF, Coday M: Identifying subgroups that succeed or fail with three levels of physical activity intervention: the Activity Counseling Trial. Health Psychol 2006, 25(3):336-347

15. Hagger MS, Chatzisarantis NLD, Biddle SJH: A meta-analytic review of the theories of reasoned action and planned behavior in physical activity: predictive validity and the contribution of additional variables. Journal of Sport and Exercise Psychology 2002, 24:3-32.

16. Wilcox S, Dowda M, Dunn A, Ory MG, Rheaume C, King AC: Predictors of increased physical activity in the Active for Life program. Preventing chronic disease 2009, 6(1):A25.

17. Plotnikoff RC, Lippke S, Karunamuni N, Eves N, Courneya KS, Sigal R, Birkett $\mathrm{NJ}$ : Co-morbidity, functionality and time since diagnosis as predictors of physical activity in individuals with type 1 or type 2 diabetes. Diabetes Res Clin Pract 2007, 78(1):115-122.

18. Godin G, Sheeran P, Conner M, Belanger-Gravel A, Gallani MC, Nolin B: Social structure, social cognition, and physical activity: a test of four models. British journal of health psychology 2010, 15(Pt 1):79-95.

19. Sallis JF, Owen N: Ecological models of health behaviour. In Health behavior and health education: theory, research, and practice 3rd edition. Jossey-Bass. San Francisco, CA; 2002:462-484.

20. Trost SG, Owen N, Bauman AE, Sallis JF, Brown W: Correlates of adults' participation in physical activity: review and update. Med Sci Sports Exerc 2002, 34(12):1996-2001.

21. Ajzen I: The Theory of Planned Behavior. Organizational Behavior and Human Decision Processes 1991, 50:179-211.

22. Armitage CJ, Conner M: Efficacy of the Theory of Planned Behaviour: a meta-analytic review. The British journal of social psychology/the British Psychological Society 2001, 40(Pt 4):471-499.

23. Symons Downs D, Hausenblas HA: The Theories of Reasoned Action and Planned Behavior applied to exercise: A meta-analytic update. Journal of Physical Activity and Health 2005, 2(1):76-97.

24. Symons Downs D, Hausenblas HA: Elicitation studies and the theory of planned behavior: a systematic review of exercise beliefs. Psychology of Sport and Exercise 2005, 6(1):1-31.

25. Conn VS, Hafdahl AR, Brown SA, Brown LM: Meta-analysis of patient education interventions to increase physical activity among chronically ill adults. Patient education and counseling 2008, 70(2):157-172

26. Williams K, Prevost AT, Griffin S, Hardeman W, Hollingworth W, Spiegelhalter D, Sutton S, Ekelund U, Wareham N, Kinmonth AL: The ProActive trial protocol - a randomised controlled trial of the efficacy of a family-based, domiciliary intervention programme to increase physical activity among individuals at high risk of diabetes [ISRCTN61323766]. BMC Public Health 2004, 4(1):48.

27. Wareham NJ, Jakes RW, Rennie KL, Schuit J, Mitchell J, Hennings S, Day NE: Validity and repeatability of a simple index derived from the short physical activity questionnaire used in the European Prospective Investigation into Cancer and Nutrition (EPIC) study. Public Health Nutr 2003, 6(4):407-413. 
28. Godin G, Shephard RJ: A simple method to assess exercise behavior in the community. Can J App/ Sport Sci 1985, 10(3):141-146.

29. Hardeman W, Sutton S, Griffin S, Johnston M, White A, Wareham NJ, Kinmonth AL: A causal modelling approach to the development of theory-based behaviour change programmes for trial evaluation. Health Educ Res 2005, 20(6):676-687.

30. Kinmonth AL, Wareham NJ, Hardeman W, Sutton S, Prevost AT, Fanshawe T, Williams KM, Ekelund U, Spiegelhalter D, Griffin SJ: Efficacy of a theorybased behavioural intervention to increase physical activity in an atrisk group in primary care (ProActive UK): a randomised trial. Lancet 2008, 371(9606):41-48.

31. Weir JB: New methods for calculating metabolic rate with special reference to protein metabolism. J Physiol 1949, 109(1-2):1-9.

32. Franks PW, Ekelund U, Brage S, Wong MY, Wareham NJ: Does the association of habitual physical activity with the metabolic syndrome differ by level of cardiorespiratory fitness? Diabetes Care 2004, 27(5):1187-1193.

33. Wareham NJ, Hennings SJ, Byrne CD, Hales CN, Prentice AM, Day NE: A quantitative analysis of the relationship between habitual energy expenditure, fitness and the metabolic cardiovascular syndrome. $\mathrm{Br} J$ Nutr 1998, 80(3):235-241.

34. Ware JE SK, Kosinski M, Gandek B: SF-36 Health Survey. Manual and Interpretation Guide Boston, MA, New England Medical Centre, The Health Institute; 1993.

35. Marteau TM, Bekker H: The development of a six-item short-form of the state scale of the Spielberger State-Trait Anxiety Inventory (STAI). Br J Clin Psychol 1992, 31(Pt 3):301-306.

36. VanDercar DH, Greaner J, Hibler NS, Spielberger CD, Bloch S: A description and analysis of the operation and validity of the psychological stress evaluator. J Forensic SCi 1980, 25(1):174-188.

37. Ajzen I: Constructing a TPB questionnaire: Conceptual and methodological considerations. 2006 [http://www.people.umass.edu/ aizen/pdf/tpb.measurement.pdf].

38. Sutton S, French D, Hennings SJ, Mitchell J, Wareham NJ, Griffin S: Eliciting salient beliefs in research on the Theory of Planned Behaviour: the effect of question wording. Current Psychology 2003, 22:234-251.

39. Wareham NJ, Jakes RW, Rennie KL, Mitchell J, Hennings S, Day NE: Validity and repeatability of the EPIC-Norfolk Physical Activity Questionnaire. Int J Epidemiol 2002, 31(1):168-174

40. Elmer PJ, Grimm R Jr, Laing B, Grandits G, Svendsen K, Van Heel N, Betz E, Raines J, Link M, Stamler J, et al:: Lifestyle intervention: results of the Treatment of Mild Hypertension Study (TOMHS). Prev Med 1995, 24(4):378-388

41. McAuley E, Courneya KS, Rudolph DL, Lox CL: Enhancing exercise adherence in middle-aged males and females. Prev Med 1994, 23(4):498-506.

42. King AC, Kiernan M, Oman RF, Kraemer HC, Hull M, Ahn D: Can we identify who will adhere to long-term physical activity? Signal detection methodology as a potential aid to clinical decision making. Health Psychol 1997, 16(4):380-389.

43. Oman RF, King AC: Predicting the adoption and maintenance of exercise participation using self-efficacy and previous exercise participation rates. Am J Health Promot 1998, 12(3):154-161.

44. Castro CM SJ, Hickmann SA, Lee RE, Chen AH: A Prospective Study of Psychosocial Correlates of Physical Activity for Ethnic Minority Women. Psychology \& Health 1999, 14:277-293.

45. Sullum J, Clark MM, King TK: Predictors of exercise relapse in a college population. J Am Coll Health 2000, 48(4):175-180.

46. Brenes GA SM, Storandt M: An application of the theory of planned behavior to exercise among older adults. Journal of Applied Social Psychology 1998, 28(24):2274-2290.

47. Caserta MS, Gillett PA: Older women's feelings about exercise and their adherence to an aerobic regimen over time. Gerontologist 1998, 38(5):602-609

48. Bouchard C, Daw EW, Rice T, Perusse L, Gagnon J, Province MA, Leon AS, Rao DC, Skinner JS, Wilmore JH: Familial resemblance for VO2max in the sedentary state: the HERITAGE family study. Med Sci Sports Exerc 1998, 30(2):252-258

49. Campbell DT, Fiske DW: Convergent and discriminant validation by the multitrait-multimethod matrix. Psychol Bull 1959, 56(2):81-105.
50. De Bourdeaudhuij I, Teixeira PJ, Cardon G, Deforche B: Environmental and psychosocial correlates of physical activity in Portuguese and Belgian adults. Public Health Nutr 2005, 8(7):886-895.

51. Giles-Corti B, Donovan RJ: The relative influence of individual, social and physical environment determinants of physical activity. Soc Sci Med 2002, 54(12):1793-1812.

52. van Sluijs EM, van Poppel MN, Twisk JW, van Mechelen W: Physical activity measurements affected participants' behavior in a randomized controlled trial. J Clin Epidemiol 2006, 59(4):404-411.

53. Ekelund U, Yngve A, Westerterp K, Sjostrom M: Energy expenditure assessed by heart rate and doubly labeled water in young athletes. Med Sci Sports Exerc 2002, 34(8):1360-1366.

54. Brage S, Wedderkopp N, Franks PW, Andersen LB, Froberg K: Reexamination of validity and reliability of the CSA monitor in walking and running. Med Sci Sports Exerc 2003, 35(8):1447-1454.

55. Bauman AE, Sallis JF, Dzewaltowski DA, Owen N: Toward a better understanding of the influences on physical activity: the role of determinants, correlates, causal variables, mediators, moderators, and confounders. Am J Prev Med 2002, 23(2 Suppl):5-14.

56. Hardeman W, Kinmonth AL, Michie S, Sutton S: Impact of a physical activity intervention program on cognitive predictors of behaviour among adults at risk of Type 2 diabetes (ProActive randomised controlled trial). Int J Behav Nutr Phys Act 2009, 6(1):16.

\section{Pre-publication history}

The pre-publication history for this paper can be accessed here: http://www.biomedcentral.com/1471-2458/10/226/prepub

doi: $10.1186 / 1471-2458-10-226$

Cite this article as: Simmons et al., Who will increase their physical activity? Predictors of change in objectively measured physical activity over 12 months in the ProActive cohort BMC Public Health 2010, 10:226

\section{Submit your next manuscript to BioMed Centra and take full advantage of:}

- Convenient online submission

- Thorough peer review

- No space constraints or color figure charges

- Immediate publication on acceptance

- Inclusion in PubMed, CAS, Scopus and Google Scholar

- Research which is freely available for redistribution 